\title{
Evaluating health care financing in a highly decentralized Beveridge model
}

\author{
Jan Klavus ${ }^{1^{*}}$, Ilkka Vohlonen ${ }^{1,2}$, Juha Kinnunen ${ }^{1}$, Veli Koistinen ${ }^{1}$, Martti Virtanen $^{3}$ \\ ${ }^{1}$ Department of Health and Social Management, University of Eastern Finland, Kuopio, Finland; \\ ${ }^{*}$ Corresponding Author: jan.klavus@audiapro.fi \\ ${ }^{2}$ Audiapro Ltd., Helsinki, Finland \\ ${ }^{3}$ Nordic Casemix Centre, Helsinki, Finland
}

Received 11 June 2012; revised 19 July 2012; accepted 25 July 2012

\section{ABSTRACT}

The Finnish health care system is financed in a highly decentralized manner. In the tax-financed Beveridge model each municipality is responseble for financing and organizing health care services for its residents. This paper examined the annual incidence and treatment costs of three cost-intensive DRG-groups, and all DRGgroups together. The objective was to estimate municipal level predictions on the incidence of new illness cases and their associated costs, and to analyze whether there was greater uncertainty in anticipated specialized health care costs in municipalities with smaller populations. The dataset comprised of longitudinal hospital utilization and discharge data from Hospital Discharge Registers. The expected annual variation of illness cases and costs was assessed with respect to $95 \%$ confidence intervals estimated for each morbidity group and municipality. The results indicated that the costs of the selected morbidity groups fluctuated in a completely uncontrollable manner in municipalities with small populations. As the median size of Finnish municipalities is less than 6000 , the inability to anticipate periodic health care costs constitutes an extensive financial problem and calls for the establishment of larger regional units and funding pools.

Keywords: Health Care Financing; Beveridge Model; Predictability of Treatment Costs; Risk Pooling

\section{INTRODUCTION}

In Finland, the financing of health care, including specialized inpatient care, is mainly based on municipal taxation. It is a highly decentralized Beveridge model. Finnish municipalities are legally obliged to finance and organize health services for their residents. There are currently 336 municipalities with a median size of less than 6000 inhabitants. This indicates the highly decentralized structure of the Finnish health care system, as well as the small size of catchment populations responseble for funding service provision.

In a widely scattered financing system municipalities face difficulties in acting in an economically systematic manner. The unpredictability of the incidence of new illness cases materializes particularly in smaller municipalities as uncontrollable annual fluctuations in health care budgets and expenditures. In small municipalities individual "cost peaks" generate more severe cash flow problems than in larger municipalities where the financing burden is distributed across larger populations. Such uncertainty causes unpredictability in budgetary planning and can lead to rising health care costs and accumulating budget deficits.

A process of restructuring the responsibilities, tasks and organization of Finnish local government is underway. In accordance with the aims of the reform the number of municipalities has been reduced from 414 in 2007 to 336 in 2010. As a general rule, smaller municipalities within an administratively cohesive catchment area have been merged into municipal organizations governed by a larger parent municipality. Along the same lines, attempts to improve the functioning, organizational structure and the financing of the health care system have been endeavoured by new legalisation (The New Health Care Act, 2011) and various reform proposals [1-3]. A common feature of all suggested reform models is the intention to consolidate the financing and provision of health care to larger regional units or a national insurance fund. The models are based on pragmatic and policy-driven approaches, and none of them are supported by economic, epidemiologic or insurance mathematical calculations or empirical analysis. 
This paper presents the findings of the VAKKA study. The study builds on an extensive database comprising of longitudinal hospital utilization and discharge data from Hospital Discharge Registers. The study aims at estimating municipal level predictions on the incidence of new illness cases, as well as their associated costs. The predicted annual variation of illness cases and costs is indicated by the width of the respective confidence intervals. The objective is to analyze empirically whether there is greater uncertainty in anticipated specialized health care treatment episodes/costs in municipalities with smaller populations, and if so, is there a cut-off point in population size after which annual variation in costs levels off.

The paper is organized as follows. The next section presents a short overview of two principal public health insurance models and outlines the main characteristics of Finnish tax-based health care financing in an European context. Section 3 describes the data and estimation methods. Section 4 presents the predicted annual variation of illness cases and treatment costs for selected diagnosis groups. The final section concludes and discusses the main policy implications of the study.

\section{PUBLIC HEALTH INSURANCE}

Particularly all developed countries apply a public financing scheme for insuring their populations for the costs of health care. Publicly financed health care systems are usually funded in one of two ways: general taxation (the Beveridge model) or social (national) health insurance contributions (the Bismarck model). In social health insurance systems, health services are funded from some combination of employees' salary deductions, employers' contributions, and possibly additional state funds. Social insurance schemes may cover other benefits besides health. Social health insurance is usually administered by sickness funds (Austria, France, Germany, Switzerland) or a central government-run fund (Luxembourg, the Netherlands) that distributes contributions to sickness funds [4]. The number of funds, their size and structure vary by country.

Tax-funded health care is based on revenue collected through general taxation. Taxes can be levied on individuals, households' and firms (direct taxes), or on commodities (indirect taxes). Direct and indirect taxes can be levied at the national regional or local levels.

Similarly to social health insurance, tax-funded health care functions principally as an insurance scheme. In a well functioning insurance scheme a large number of contributors (pooling fund) offer financial protection against unreasonable high health care costs for any individual insured. In a broader perspective the risk-pooling principle concerns not only individuals using health care services but also the agents responsible for fund pooling, and the organizers and providers of health services. In case the size of the pooling fund is not sufficiently large, and insurance premiums cannot be allocated over time, costs of the insurance scheme tend to rise and the scheme operates under higher unpredictability of risk. The premiums and operating costs associated with the scheme may vary significantly from one period to another [5].

The funding of health and social services in Finland comprises of revenue collected through general taxation $(65 \%)$, sickness insurance contributions (15\%) and outof-pocket payments $(20 \%)$. In addition to the fiscal financing system, the social insurance scheme administered by Kela, collects payroll taxes that finance old-age pensions, a range of income transfers and reimbursements for private health services and prescription drugs.

Revenue is collected through a mixture of municipal income taxes, state taxes (income and commodity taxes) and user charges. In the system of locally administered service provision municipalities act as autonomous pooling funds. The funds are prospectively allocated through an annual budgetary plan/process to purchase needed health and social services. The Finnish health care system resembles those of other Nordic countries. It offers universal coverage for a comprehensive range of health services delivered primarily by publicly owned and operated providers. However, the Finnish system is clearly more decentralized in its organizational structure than those of the other Nordic countries [6].

In the decentralized municipal health care system, organizational responsibility is distributed across $336 \mathrm{mu}-$ nicipalities and 20 hospital districts. In 2007 the average population in a municipal pooling fund was less than 16,000 (Table 1). In the European Union context, Finland stands out as a country with exceptionally small size of pooling funds. For example, France and England occupy a single national fund covering their total populations of over 60 million people. In Germany with the highest number of pooling funds after Finland, the average size of members per fund was over 400,000 in 2007.

In most Member States publicly collected health care funds are pooled at the national level. Exceptions are Member States where local taxes are used to finance health care and those where individual health insurance funds are responsible for the collection of insurance contributions. There is a clear trend in Europe towards creating national pools. For example from 2009 social insurance contributions in Germany have been pooled nationally by the new national health insurance fund.

\section{METHODOLOGY AND MATERIALS}

The main data source consisted of the Hospital Discharge Registers (HILMO) received from the seven hospital districts that participated in the study. The hospital districts and available data years are presented in Table 2. 
Table 1. Risk pooling and service provision in EU Member States.

\begin{tabular}{|c|c|c|c|c|}
\hline & \multicolumn{2}{|c|}{ Funders } & \multicolumn{2}{|c|}{ Purchasers } \\
\hline & Pooling & Population/ & & Population/ \\
\hline & Funds & Pooling fund & Purchasers & Purchasers \\
\hline Finland & 336 & 15,795 & 336 & 15,795 \\
\hline Greece & 30 & 374,000 & 30 & 374,000 \\
\hline Austria & 21 & 397,000 & 21 & 397,000 \\
\hline Malta & 1 & 406,000 & 1 & 406,000 \\
\hline Germany & 200 & 411,000 & 200 & 411,000 \\
\hline Sweden & 21 & 439,000 & 21 & 439,000 \\
\hline Luxembourg & 1 & 471,000 & 9 & 52,000 \\
\hline Cyprus & 1 & 793,000 & 1 & 793,000 \\
\hline Slovakia & 6 & 899,000 & 6 & 899,000 \\
\hline Denmark & 5 & $1,098,000$ & 5 & $1,098,000$ \\
\hline $\begin{array}{l}\text { Czech } \\
\text { Republic }\end{array}$ & 9 & $1,140,000$ & 9 & $1,140,000$ \\
\hline Estonia & 1 & $1,340,000$ & 4 & 335,000 \\
\hline Slovenia & 1 & $2,010,000$ & 1 & $2,010,000$ \\
\hline Spain & 20 & $2,216,000$ & 20 & $2,216,000$ \\
\hline Latvia & 1 & $2,271,000$ & 8 & 284,000 \\
\hline Italy & 20 & $2,943,000$ & 20 & $2,943,000$ \\
\hline Lithuania & 1 & $3,366,000$ & 5 & 673,000 \\
\hline Ireland & 1 & $4,250,000$ & 1 & $4,250,000$ \\
\hline Bulgaria & 1 & $7,538,000$ & 28 & 269,000 \\
\hline Hungary & 1 & $10,035,000$ & 1 & $10,035,000$ \\
\hline Belgium & 1 & $10,517,000$ & 7 & $1,502,000$ \\
\hline Portugal & 1 & $10,620,000$ & 5 & $2,124,000$ \\
\hline Netherlands & 1 & $16,390,000$ & 19 & 863,000 \\
\hline Romania & 1 & $22,215,000$ & 42 & 529,000 \\
\hline Poland & 1 & $38,116,000$ & 1 & $38,116,000$ \\
\hline England & 1 & $60,520,000$ & 152 & 398,000 \\
\hline France & 1 & $61,840,000$ & 3 & $20,613,000$ \\
\hline
\end{tabular}

Source: S. Thomson, T. Foubister, E. Mossialos. Financing Health Care in Europe [7].

Register data from all the hospital districts were merged and classified using the 2009 NordDRG-grouper. The number of unclassified patient cases was identified and compared on a yearly basis with respect to MDCgroups in the hospital districts own register data. In addition, a check-up was run in order to make sure that the
Table 2. Hospital discharge register (HILMO) data.

\begin{tabular}{cc}
\hline Hospital/ & Hospital Discharge Register/ \\
\hline Health district & Years \\
\hline Etelä-Savo & $2001-2009$ \\
Etelä-Karjala & $2003-2009$ \\
Carea & $2002-2009$ \\
HUS (Helsinki and Uusimaa & $2002-2010$ \\
Hospital district) & $2000-2010$ \\
Pohjos-Pohjanmaa & $2002-2010$ \\
Päijät-Häme & $2002-2007$ \\
Keski-Suomi &
\end{tabular}

MDC-group 99 (erroneous, obscure) was not exceptionally large.

The HILMO-registers contained hospital utilization data on $125(35 \%)$ Finnish municipalities. In terms of population coverage VAKKA-data represented about half (49\%) of the total Finnish population.

The dataset was a representative sample of the Finnish population. In comparison to the population distribution of all Finnish municipalities, VAKKA-data corresponded rather closely to the percentage shares of municipalities of various sizes in the overall distribution. The dataset had a slightly more even size distribution, but this difference was negligible in the framework of the current analysis. The data corresponded rather closely to the gender distribution of the population. With respect to age structure, a slight difference in the population shares of the oldest age group existed. The VAKKA-data contained a somewhat smaller share of population over 65 -year-old (13\%) in comparison to the total population $(17 \%)$. This was mainly due to the effect of the large HUS hospital district (greater Helsinki area and neighboring municipalities).

The morbidity indicators (DRGs) applied in the study were selected among those diagnosis groups that were expected to create an unpredictable and significant financial burden for a municipality.

This burden could be generated by the incidence of a single high-cost treatment episode or by the long duration of several semi-costly episodes and the associated treatment costs. The selection process emphasized the identification of indicators with a high degree of consistency and a low impact of supplier induced demand. In addition the estimations were carried out for all DRGs together. The ten morbidity indicators were:

014A Specific cerebrovascular disorders except TIA with cc

014B Specific cerebrovascular disorders except TIA w/o cc

209A Major joint procedures of lower extremity, not 
reoperation

122 Other circulatory disorders with ami without cardiovascular complications, alive at 4 th day of care

167 Appendectomy w/o complicated principal diag w/o cc

183 Esophagitis, gastroent \& misc digest disorders, age $>17 \mathrm{w} / \mathrm{o} \mathrm{cc}$

436B Other abuse disorders w/o cc

373 Vaginal delivery w/o complicating diagnoses

039A Lens procedures with or without vitrectomy

ALL All DRGs together

Due to space limitations, only three morbidity indicators and all DRGs together were analyzed in the present study (014B, 122, 209A and ALL).

In the first stage the annual incidence of the indicators was calculated for each municipality. In the second stage the expected value and 95\% confidence intervals were estimated from data covering all the study years. These confidence intervals were interpreted as the interval within which the number of new illness cases in the next period will lie with a $95 \%$ probability.

The confidence intervals $(C I)$ were estimated as follows:

$$
C I=\bar{x} \pm 1.96 \frac{s}{\sqrt{n}}
$$

The standard error of the mean ( $s$ ) describes the accuracy of the sample mean and it is used to measure the width of the confidence interval corresponding to a certain probability level.

In the third stage the costs of treatment for each morbidity indicator were calculated. The treatment costs per morbidity indicator were calculated using the associated DRG-weights and the average DRG-price. The average DRG-price of the HUS hospital district was used as reference.

Similarly to the interpretation of the confidence interval described before, this estimate was considered to indicate the interval within which costs by morbidity group were expected to lie in the next budgetary period. Costs of preceding years were converted to constant 2010 Euros using the hospital cost index published by the Statistics Finland [8].

The following example will help to clarify the estimation method. According to the HILMO-registers of the Etelä-Savo hospital district, a total of 1024 uncomplicated brain infarctions (DRG 014B) occurred in the municipality of Mikkeli in 2001-2009. On the average there were 114 such episodes per year (1024/9). As the incidence of brain infarctions is subject to random variation, the incidence of new cases will vary by year. Taking into account the random element in the occurrence of new treatment episodes, the confidence interval associated with this morbidity indicator ranged from 98 to 130 episodes. Consequently, the number of brain infarctions in the Mikkeli municipality was estimated (with a 95\% probability) to be at the minimum 98 and at the maximum 130 episodes per year. The expected annual costs of brain infarctions were $€ 287,175 \quad((=114 *$ (average cost*DRG-weight*price index 2010)) and the expected variation of costs $€ 235,655$ - 338,655.

In the present study the annual variation of costs per 1000 inhabitants was analyzed by the relationship of the standard error of the mean and the size of the population of each municipality. The aim of this analysis was to examine if the annual variation in treatment episodes and costs was larger in municipalities with smaller populations. In other words, is it more difficult for a small municipality to assess beforehand the future costs of specialized health care than for a bigger municipality? The analysis is presented in the next section using scatter grams.

A linear regression line was fitted in the diagrams. This line gives an indication of the "trend" prevailing between the magnitude of the annual variation of treatment episodes (or their associated costs) and population size. A decrease in the annual variation with an increase of the population size of a municipality was expected. The linear regression model simplifies the true relationship and the regression line should not be interpreted as an accurate prediction of annual costs for a certain population size.

\section{RESULTS}

In order to examine more closely the random element in the incidence of new treatment episodes, the incidence of uncomplicated brain infarction in the municipalities of the Etelä-Savo hospital district was analyzed. Annual new brain infarction episodes per 1000 inhabitants were more frequent in municipalities with small populations (Juva, Suomenniemi) (Table 3).

In municipalities with larger populations the incidence of brain infarction was clearly smaller, about half of that of small municipalities, being 233 and 453 cases per 1000 inhabitants.

In the smaller municipalities the higher incidence of brain infarction was accompanied by greater annual variance. In the smallest municipality the range of new treatment episodes varied by 301 cases per year, while in the biggest municipality, the range of variation was 33 cases per year (see Table 3 ).

Correspondingly the annual treatment costs of new treatment episodes per 1000 inhabitants were highest in the two smallest municipalities (Table 4).

As the population of the municipality increased, the annual variation of treatment costs decreased. In the 
Table 3. Incidence and annual variation (+/-) of brain infarction (DRG 014B) in four municipalities of the Etelä-Savo hospital district (cases/1000 inhabitants).

\begin{tabular}{cccccc}
\hline Municipality & Population & \multicolumn{2}{c}{ DRG (014B) } \\
\hline & 2010 & & At lower bound of & At upper bound of & Range of \\
& & Average/ & Confidence interval/ & Confidence interval/ & Confidence interval/ \\
& & 1000 inhabitants & 1000 inhabitants & 1000 inhabitants & 1000 inhabitants \\
Mikkeli & 48,688 & 2.33 & 2.00 & 2.66 & $+/-0.33$ \\
Pieksämäki & 20,151 & 2.42 & 2.07 & 2.76 & $+/-0.35$ \\
Juva & 7,499 & 4.02 & 3.22 & 4.83 & $+/-0.80$ \\
Suomenniemi & 843 & 4.53 & 1.52 & 7.53 & $+/-3.01$ \\
\hline
\end{tabular}

Table 4. Treatment costs and annual variation (+/-) of brain infarction (DRG 014B) in four municipalities of the Etelä-Savo hospital district (€/1000 inhabitants).

\begin{tabular}{|c|c|c|c|c|c|}
\hline \multirow[t]{4}{*}{ Municipality } & Population & \multicolumn{4}{|c|}{ DRG (014B) } \\
\hline & & & At lower bound of & At upper bound of & Range of \\
\hline & & Average/ & Confidence interval/ & Confidence interval/ & Confidence interval/ \\
\hline & & 1000 inhabitants & 1000 inhabitants & 1000 inhabitants & 1000 inhabitants \\
\hline Mikkeli & 48,688 & 5880 & 4895 & 6865 & $+/-985$ \\
\hline Pieksämäki & 20,151 & 6110 & 5058 & 7161 & $+/-1052$ \\
\hline Juva & 7499 & 10,256 & 7744 & 12,769 & $+/-2512$ \\
\hline Suomenniemi & 843 & 11,697 & 3864 & 19,530 & $+/-7833$ \\
\hline
\end{tabular}

biggest municipality the annual variation of costs was $€ 985$ (about 17 percent of average treatment costs) while it was $€ 7833$ in the smallest municipality (about 67 percent of average treatment costs).

The municipality with a population of less than 1000 had in the worst case to prepare for about $€ 20,000$ annual treatment costs of uncomplicated brain infarctions per 1000 inhabitants. In the two biggest municipalities with populations in the range of 20,000 and 50,000 the uncertainty related treatment costs would at their highest reach $€ 7000$ per 1000 inhabitants.

The greater uncertainty regarding the incidence and treatment costs of brain infarction in smaller municipalities can be observed more generally in an analysis involving all the municipalities (under 100,000 inhabitants) in the dataset (Figure 1(a)). The magnitude of the annual variation of treatment costs of brain infarctions as measured by the standard error fluctuated randomly in the smallest municipalities. In municipalities with a population of less than 10,000 the annual fluctuation of costs could be almost non-existent, but at the same time in other equally small municipalities, it could reach ex- tremely high values.

The fluctuation in the annual variation of treatment costs decreased as the population of the municipality approached 20,000, and fell further when the population reached 40,000 and above. However, for populations larger than 40,000 inhabitants, no clear tendency towards a systematically diminishing periodic fluctuation of costs could be observed. This relationship was very similar as regards the other morbidity indicators. When all DRGS were analyzed together a similar pattern occurred, but the standard errors were more widely scattered along the vertical axis (Figures 1(b)-(d)).

The inverse relationship between population size and the annual variation of treatment costs could be observed more clearly when the population axis was cut-off at 100,000 inhabitants. Including all municipalities (even those over 100,000 inhabitants) the trend line for all DRGs together was still declining (Figure 2). However, as observations on municipalities with populations over 100,000 were very few in number, the interpretation of the relationship at the upper end of the population distribution was not meaningful. For the same reason, it was 


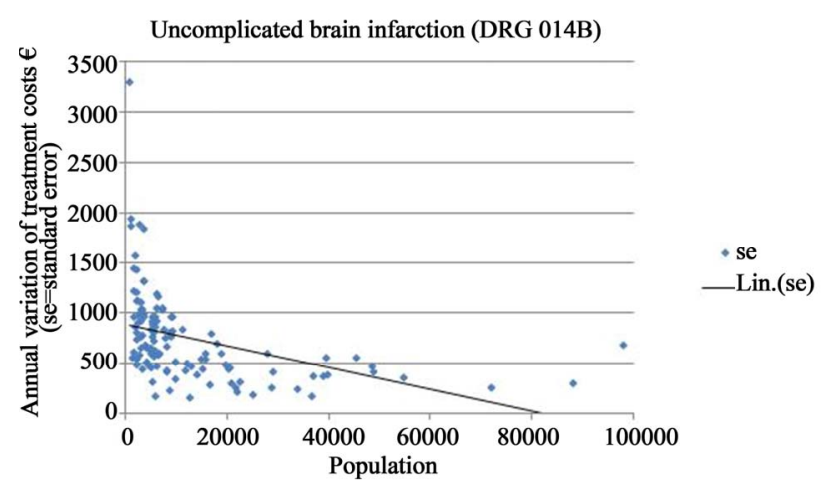

(a)

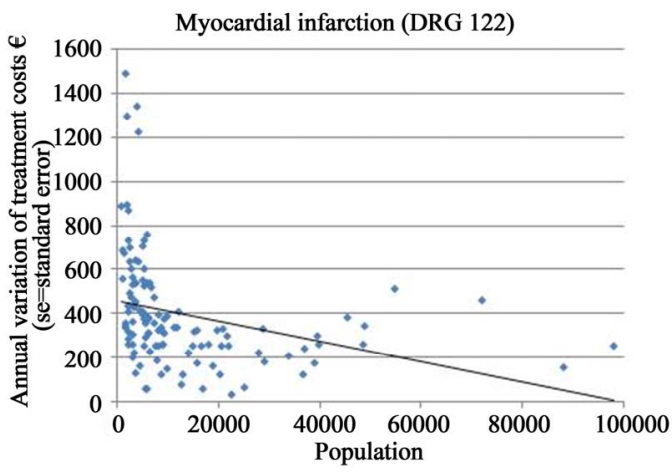

(b)

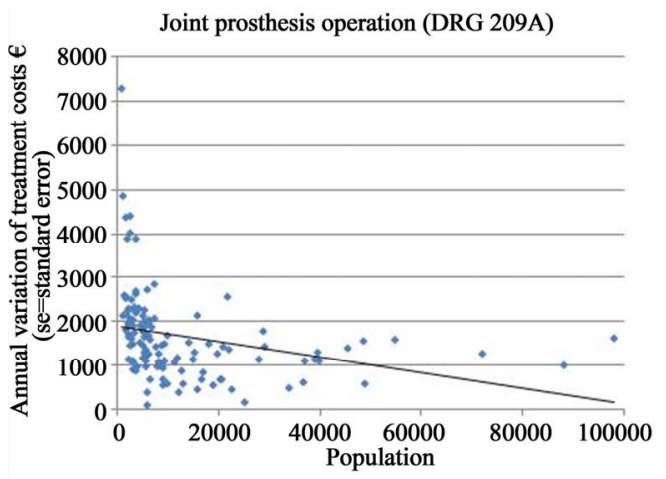

. se $-\operatorname{Lin}(\mathrm{se})$

(c)

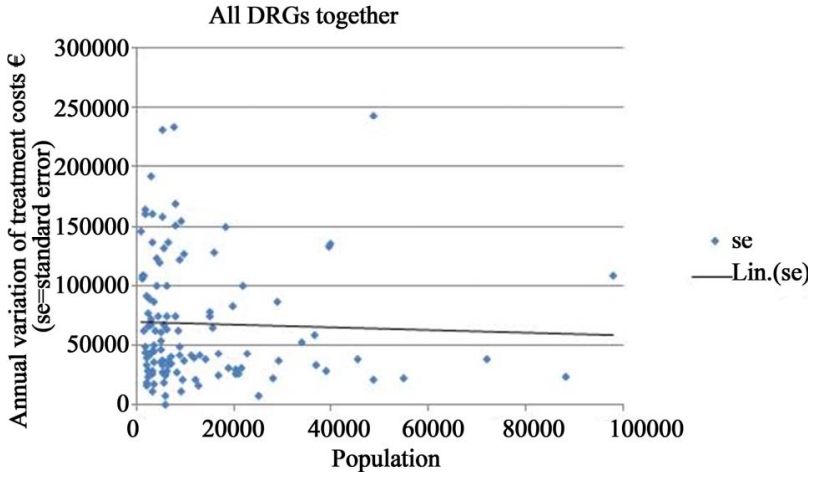

(d)

Figure 1. Annual variation of treatment costs of selected DRGs in Finnish municipalities of under 100,000 inhabitants $(€ / 1000$ inhabitants; se $=$ standard error; Lin. $(\mathrm{se})=$ trend line).

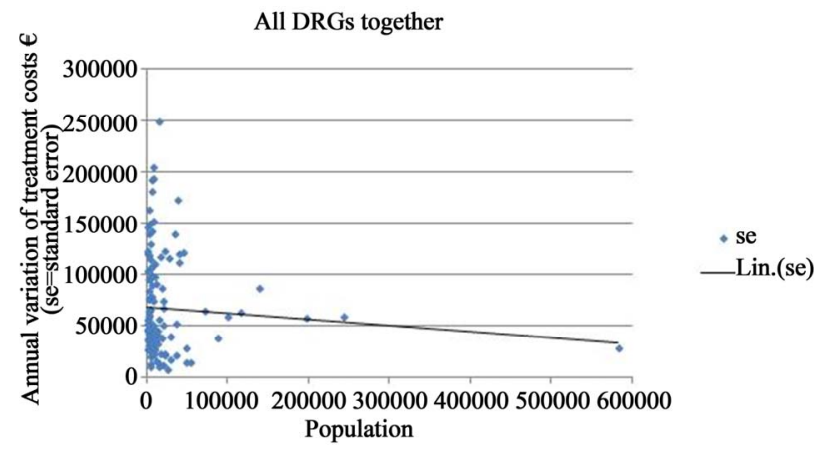

Figure 2. Annual variation of treatment costs of all DRGs together in Finnish municipalities $(€ / 1000$ inhabitants; se $=$ standard error; Lin. $(\mathrm{se})=$ trend line).

not statistically possible to estimate an optimal size of the pooling fund in the present analysis.

\section{CONCLUSIONS AND DISCUSSION}

The study indicated that the annual incidence and treatment costs of the most cost-intensive morbidity groups fluctuated in a completely uncontrollable manner in small municipalities. The annual variation was largest in municipalities with populations under 10,000 inhabitants. The fluctuation in the annual variation of treatment costs decreased as the population of the municipality approached 20,000 and diminished further at populations of 40,000 and beyond. Further, the analysis suggested that the predictability of specialized health care costs may not significantly improve when the size of the catchment population exceeds 100,000 inhabitants.

As about three fourths of Finnish municipalities have populations of less than 10,000 inhabitants, the inability to foresee the periodic costs of specialized health care constitutes a serious and wide-spread financial problem. This uncertainty is likely to undermine health care resources and reflect to the sufficiency and quality of health services as well as other public services. On the other hand, the study suggested that very large populations do not necessarily guarantee a further reduction in the variation of treatment costs. Therefore, if the primary policy criterion is the minimization of the risk of unpredictable financial burdens, a nationally administered health care funding scheme is not self-evidently supported.

The traditional Beveridge model, the way it is applied in the Finnish decentralized health care financing system, does not function as intended. Individual municipalities are too small entities for constituting sufficiently large risk-sharing pools that would protect them from financial uncertainty. Schemes like the state subsidy system and the compensation system for treatment of extremely costly patients offer protection mechanisms that can to some degree alleviate the risks of cost variation. How- 
ever, these mechanisms are either too small-scaled (state subsidies) or exclusive with respect to compensation criteria (costly patients) for providing sufficient insurance coverage for municipalities.

The ongoing reform of local government structures is in accordance with the findings of the study; larger municipal entities enable larger catchment populations and promote wider risk-sharing pools. However, reforming of the financing structures of primary and specialized health care should be carried out simultaneously with the establishment of such larger municipal organizations. In the current situation a comprehensive strategy comprising a reconciliation of the various organizations, schemes and functions of health care (and social care) is more or less missing.

The analysis showed that existing register data sources on health care utilization and costs enable the provision of research based evidence to support a critical assessment of various policy alternatives for health care financing. The models presented in this study, and their future developments, can be used for determining a sufficient population size that will enable better administration and predictability of health care costs. In accordance with the need to avoid piecemeal reforms, the VAKKAproject will continue to provide topical research evidence for policy purposes. In the next phase the findings and materials of the current study will be utilized in analyzing and calculating the prerequisites of profitable production units in specialized health services (TUOTAproject).

\section{REFERENCES}

[1] Huuhtanen, J. (2005) The Kela model on the financing and organization of health services (in Finnish). PowerPoint Presentation, Helsinki.

[2] Aronkytö, T., Hallipelto, A. and Kangasharju, A. (2010) A new health care financing and organization scheme (in Finnish). SITRA Reports 24, Helsinki.

[3] National Institute for Health and Welfare (2010) The advantages, drawbacks and development requirements of the multi-channeled health care financing system (in Finnish). Report by the THL Expert Panel, Helsinki.

[4] Figueras, J., Saltman, R.B., Busse, R. and Dubois, F.W. (2004) Patterns and performance in social health insurance systems. In: Saltman, R.B., Busse, R. and Figueras, J., Eds., Social Health Insurance Systems in Western Europe. Open University Press, Berkshire, 81-140.

[5] Busse, R., Saltman, R. and Dubois, H. (2004) Organization and financing of social health insurance systems: Current status and recent policy developments. In: Saltman, R.B., Busse, R. and Figueras, J., Eds., Social Health Insurance Systems in Western Europe. Open University Press, Berkshire, 33-81.

[6] Teperi, J., Porter, M.E., Vuorenkoski, L. and Baron, J.F. (2009) The Finnish Health Care System: A value based perspective. Sitra Reports 82, Helsinki.

[7] Thomson, S., Foubister, T. and Mossialos, E. (2004) Financing health care in the European Union: challenges and policy responses. Observatory Studies Series, 17.

[8] Statistics Finland (2010) Public expenditures price index. http://www.stat.fi/til/jmhi/ 